\title{
Changing scenario of postgraduate medical education in Nepal
}

Nepal BP

Up to merely a decade ago, Nepal was largely dependent upon other countries (mainly India) for postgraduate medical education. Medical graduates had to wait for as long as ten years for a chance to pursue postgraduate education and had to accept any subject they could get, as the opportunity for postgraduate study was few and far between. The scenario has completely changed and Nepalese medical graduates do not have to look to other countries for their specialist medical training any more. The number of postgraduate studies available has also grown in number, quality, and grades in various fields of medicine and continues to do so.

The Institute of Medicine under Tribhuvan University started its first training for postgraduates in General Practice in 1982; Ophthalmology in 1987; and in other subjects thereafter. Today, they have also added MCh and PhD in some subjects. The Post Graduate Medical Education Coordination Committee, under the Ministry of Health, started its postgraduate programme in the Valley group of hospitals in 1994 which was later converted into National Academy of Medical Sciences in 2003. 1,2 $^{1}$ They have also added DM programme in some clinical science subjects in 2010. The B P Koirala Institute of Health Sciences started its postgraduate programme in 1999 and continues to grow.

Kathmandu University (KU) first offered postgraduate medical education with its MS Orthopaedics degree at B\&B Hospital in 1999; MCh Neurosurgery at Bir Hospital in 2000; MD Pathology at Manipal School of Medical Sciences, Pokhara in 2000; MD Pathology at Kathmandu Medical College in 2003; and MSc (Medical) in basic medical science subjects at the College of Medical Science, Bharatpur in 2003. When KU recognised that there was an acute shortage of faculties at existing medical colleges already attached to hospitals, but which were growing in numbers swiftly, it entered into an agreement with Manipal Education and the Medical Group of India in 2003 for medical doctors who wanted to continue their postgraduate education. This postgraduate programme continues today and has contributed hugely towards faculty development in Nepal.

$\mathrm{KU}$ has updated its own postgraduate medical programmes (MD/MS) in various clinical and non-clinical subjects at Manipal College of Medical Science, Pokhara; the College of Medical Science, Bharatpur; and Nepalgunj Medical College, Nepalgunj; from the year 2007. Likewise, in 2009 clinical and non-clinical programmes were launched at Kathmandu Medical College, Sinamangal, and Nepal Medical College, Atterkhel. KU has also revived its MSc (Medical) programme in 2010 to meet the demands required of faculties in basic medical science subjects. KU started DM/MCh programmes in some subjects at the College of Medical Science, Bharatpur in 2009. MCh in Neurosurgery under KU is also in progress at the Institute of Neuroscience, Kathmandu at present.

Up to 2006, Nepal Medical Council; a regulatory body for medical education in Nepal; only regulated the MBBS undergraduate programmes in the ever-growing number of medical colleges throughout Nepal. It has also taken charge of the MD/MS postgraduate medical programme and developed "Regulations for Post-graduate Medical education". ${ }^{3}$ 
However, Nepal Medical Council still needs to develop regulations for the DM/MCh programmes already up-and-running at the Institute of Medicine, National Academy of Medical Sciences and Kathmandu University in order to encourage development.

The Medical Colleges in Nepal are at present largely dependent on India for supply of faculties in both clinical and non-clinical subjects. The shortage is more acutely felt in nonclinical subjects, even in medical colleges within Kathmandu Valley. Postgraduate students of our own universities have now started to fill vacancies at our institutes from a junior level. It should still be acknowledged that it will take at least another ten years before Nepal becomes self-sufficient in its supply of internally-educated postgraduate specialist doctors, and medical colleges should not become complacent.

It is important to keep an eye on the quality of education to ensure that the products of our medical colleges are of the highest standard. Universities and the Nepal Medical Council must keep a constant vigil to ensure that at least the minimum standards of postgraduate medical education in Nepal are upheld.

It is worth noting however, that the medical fraternity of Nepal should be proud that even whilst the country was plagued by insurgency over the last decade; and even whilst the overall development of the country was pushed back wards; medical education including postgraduate education continues to be unaffected and grows swiftly. Its benefits can be seen by all, none more so than the Nepalese people; who are provided health services at their door steps by medical college hospitals and their outreach clinics. Its effects have not only attracted Nepalese doctors for postgraduate education in our own country without much of a wait, but also doctors from India, Sri Lanka, the Maldives, Bhutan, Cambodia and other countries who are benefitting and will continue to benefit from our graduate and postgraduate programmes.

\section{REFERENCES}

1. Karki DB. Quo Vadis- Post graduate Medical Education in Nepal. Kathmandu Univ Med J 2003;1(1):1-2.

2. Karki DB, Dixit H. An Overview of Under graduate and Post graduate Medical Education in Nepal and Elsewhere. Kathmandu Univ Med J. 2004; 2(1):69-74.

3. Nepal. Regulation for Post-graduate Medical Education. Bansbari, Kathmandu: Nepal Medical Council; 2006. 